\title{
NARRATIVAS (AUTO) BIOGRÁFICAS DAS REDIMENSÕES DA PRÁTICA PEDAGÓGICA NOS PRIMEIROS ANOS DA DOCÊNCIA NO ENSINO SUPERIOR
}

\author{
A. N. O. FERNANDES E N. F. M. A MEDEIROS \\ Instituto Federal de Educação, Ciência e Tecnologia do Rio Grande do Norte - IFRN \\ Universidade do Estado do Rio Grande do Norte - UERN \\ aleksandranogueira@outlook.com*
}

Artigo submetido em agosto/2015 e aceito em fevereiro/2016

DOI: $10.15628 /$ holos.2016.3284

\begin{abstract}
RESUMO
A pesquisa aqui apresentada tem como objetivo analisar as redimensões da minha prática pedagógica no estágio supervisionado, nos primeiros anos da docência no Ensino Superior. Utilizei o método (auto) biográfico apoiada, principalmente, em Josso (2010), que discute sobre a pesquisa formação, e Zabalza (2004), que aborda sobre o diário de aula, de que faço uso para refletir sobre as minhas narrativas como professora de estágio. Outros nomes, entretanto, se destacam no estudo, entre eles, Veiga (1994); Libâneo (1994); Luckesi (1994); Freire (1996); Tardif (2012), Pimenta e Lima (2010); Farias (2009) e Marcelo (1999). O diário é um documento em que
\end{abstract}

professores e professoras anotam suas impressões sobre o que vai acontecendo em suas aulas. Dessa maneira, os resultados tornam-se latentes. A exemplo, cito a metodologia por mim utilizada na disciplina de estágio na educação infantil, de 2010 a 2014, no curso de Pedagogia da Faculdade de Educação - FE, da Universidade do Estado do Rio Grande do Norte - UERN, que se modificou com a experiência. Antes, não possuía abertura para o diálogo e era focada nas técnicas de ensino, mas, no contato com os alunos e demais professores, compreendi que a aprendizagem é algo coletivo, contínuo e que requer problematização (FARIAS 2009).

PALAVRAS-CHAVE: (Auto) biografia. Prática pedagógica. Estágio supervisionado.

\section{(SELF) BIOGRAPHIC NARRATIVES OF PEDAGOGICS PRACTICES REMODELATIONS IN THE FIRST YEARS OF SUPERIOR EDUCATION TEACHING}

\begin{abstract}
This present research aims to analyze the remodelation on my pedagogics practices in Supervised Traineeship in my first years as a teacher in superior education. I have used the (self) biographic methodology, theoretically based mainly in Josso (2010) who discusses about the formation research and Zabalza (2004) who approaches about the classroom journal, which I used to rethink on my narratives as traineeship teacher. Among different authors, we based our study on Veiga (1994); Libâneo (1994); Luckesi (1994); Freire (1996); Tardif (2012), Pimenta and Lima (2010); Farias (2009) and Marcelo (1999). The journal is a document in which the teachers
\end{abstract}

write down their impressions about what is happening in the classroom. As a consequence, meaningful results were accomplished. The example is the methodology I used in the child education traineeship subject in Pedagogics course in the Education College - at Rio Grande do Norte State University - UERN from 2010 to 2014, has changed with the experience. Before that I had no interest in dialoguing on this subject and was too much focused on teaching techniques. However, with this contact with students and teachers, I could comprehend that learning process is something collective, continuous and demands problematization (FARIAS 2009).

KEYWORDS: (Self) biography. Pedagogics Practices. Supervised Traineeship. 


\section{INTRODUÇÃO}

Neste artigo reflito sobre as redimensões da minha prática pedagógica no estágio supervisionado, nos primeiros anos da docência no Ensino Superior. Quando analiso a minha prática pedagógica no ensino superior, acredito ser importante trazer um conceito do que seria essa prática, ou seja, "[...] a prática pedagógica é uma prática social orientada por objetivos, finalidades e conhecimentos, e inserida no contexto da prática social. [...] é uma dimensão da prática social que pressupõe a relação teoria-prática" (VEIGA, 1994, p. 16).

Esta proposta é parte da minha dissertação de mestrado, onde discuto sobre as redimensões da prática pedagógica em fase inicial na docência universitária, na Faculdade de Educação - FE da Universidade do Estado do Rio Grande do Norte - UERN, por meio das narrativas (auto) biográficas.

Assim, farei, aqui, algumas reflexões sobre as minhas narrativas (auto) biográficas em relação ao exercício da atividade docente no Ensino Superior, dando ênfase à metodologia utilizada com os alunos no curso de Pedagogia da FE/UERN de 2010 a 2014.

Em relação à metodologia, esse elemento me fez repensar sobre como organizava as minhas aulas no início da docência, quando percebi a minha preocupação apenas com o repasse dos conteúdos naquele primeiro momento. Com o passar do tempo, ao longo do meu desenvolvimento profissional, fui rompendo com uma concepção tecnicista e passei a redirecionar a maneira de dar aulas, começando a valorizar o diálogo em sala de aula, como também a refletir sobre o item avaliação.

Aqui, faço uso da (auto) biografia como método de investigação. Esse método é um tanto desafiante, pois rompe com a lógica positivista, trazendo as subjetividades dos sujeitos para a ordem do dia. Escolhi a pesquisa (auto) biográfica por ser entendida como dispositivo reflexivo na formação docente, pois o professor, ao narrar suas experiências profissionais, transforma as representações de si e de sua prática pedagógica (PASSEGGl et al, 2006).

Nesta perspectiva, as narrativas (auto) biográficas permitem ao professor compreender melhor porque está na profissão, se constituindo num valoroso instrumento para pensar sobre o aprender a formação.

Como instrumento de pesquisa para a produção de dados, reflito sobre os meus diários de aula, dos quais faço uso para refletir sobre as minhas narrativas como professora de estágio. $O$ diário é um documento em que professores e professoras anotam suas impressões sobre o que vai acontecendo em suas aulas. Segundo o autor, não precisam, necessariamente, ser escritos diariamente, podem ser redigidos duas vezes por semana, alternando os dias. São narrações construídas por professores efetivos ou em formação, logo, o conteúdo do diário pode ser aberto ou condicionado a um planejamento prévio e o eixo fundamental da escrita é o contexto da aula no âmbito da atividade docente (ZABALZA, 2004).

Como principal interlocutora da pesquisa, por meio do diário autobiográfico, descrevo reflexivamente as minhas experiências como professora do estágio na educação infantil, compreendendo o período de 2010 a 2014 do referido curso, me auto avaliando e me auto 
formando.

A fundamentação teórica que norteou esta experiência parte das ideias de alguns teóricos, como: Josso (2010); Zabalza (2004); Veiga (1994); Libâneo (1994); Luckesi (1994); Freire (1996); Tardif (2012); Pimenta e Lima (2010); Farias (2009); Marcelo (1999); entre outros.

\section{DISCUTINDO SOBRE O ESTÁGIO SUPERVISIONADO I NO CURSO DE PEDAGOGIA DA FE/UERN: O LUGAR DE ONDE EU FALO}

De acordo com seu Projeto Pedagógico (PPC), o curso de Pedagogia da Universidade do Estado do Rio Grande do Norte - UERN é um curso de graduação na modalidade licenciatura, abrangendo as seguintes áreas de conhecimento: Ciências Humanas e Sociais.

O curso foi criado pela Resolução 126/66 - CEE, de 16/11/1966, tendo iniciado seu funcionamento em 28/09/1967, pelo Decreto Federal no 72263/73, de 15/05/1973. A carga horária total é de 3205 h e o tempo médio de integralização curricular é de 04 a 06 anos, no máximo. Oferece 120 vagas iniciais, sendo 60 para o primeiro semestre e 60 para o segundo. 0 funcionamento é diurno e noturno, comportando, no máximo, 40 alunos por turma. Funciona no Campus Universitário Central, na Rua Professor Antônio Campos, s/n - BR 110, Km 46, no Bairro Costa e Silva, em Mossoró - RN. Neste sentido:

O Curso de Pedagogia ofertado pela Faculdade de Educação da Universidade do Estado do Rio Grande do Norte - FE/UERN originou-se em 1967 com uma turma de Administração Escolar. Posteriormente, passou a oferecer também turmas para Estudo das Disciplinas e Atividades Práticas - EDAPE. Foi reconhecido em 1973, por meio do Decreto no 72.263, de 15 de maio de 1973 (ANEXO 1), com as habilitações: Magistério das Matérias Pedagógicas do 20 Grau e Administração Escolar do 10 e 20 Graus. No ano seguinte, passou a ofertar mais uma habilitação: Supervisão Escolar (1974) e quatro anos após, passou a ofertar a habilitação de Orientação Educacional (1978) (PPC do curso de Pedagogia, 2012, p. 08).

No início do ano de 1990, a Faculdade de Educação - FE participou, junto com outras instituições e entidades que discutem sobre a formação do pedagogo no país, de um grande processo de discussão sobre o curso de Pedagogia. Cinco anos depois, em 1995, ocorreu uma reformulação curricular, suspendendo a oferta das habilitações anteriores e sendo criada a habilitação voltada para a docência nos anos iniciais do Ensino Fundamental.

Em decorrência dessas mudanças, surgiram várias críticas, principalmente pela restrição da atuação profissional, por estar habilitado somente ao exercício do magistério nos anos iniciais do Ensino Fundamental. Essa situação, aliada ao debate nacional, fomentou as discussões curriculares no interior da $\mathrm{FE}$, repensando a formação do pedagogo, no sentido de ampliar o seu campo de atuação profissional.

Assim, a partir de 2002, os debates se intensificaram por força das Diretrizes Curriculares Nacionais para a Formação de Professores da Educação Básica. Entre 2002 e 2006 foram definidas necessidades e demandas para a formação dada no Curso de Pedagogia. Novas discussões passaram 
a envolver a comissão de currículo da FE e dos Campi Avançados. Atualmente, o objetivo do curso de Pedagogia é:

Formar pedagogos para atuarem na docência da Educação Infantil, Anos Iniciais do Ensino Fundamental, Educação de Jovens e Adultos e na gestão dos processos educativos, nos espaços escolares e não escolares, que impliquem o trabalho pedagógico. Produção do conhecimento inerentes à natureza das práticas educativas escolares e não-escolares (PPC do curso de Pedagogia, p. 22, 2012).

Hoje, o currículo encontra-se organizado da seguinte maneira: disciplinas introdutórias, fundamentos, especialização, aprofundamento e aplicação tecnológica, a fim do estudante (re) elaborar os conhecimentos inerentes à atuação do pedagogo.

Neste sentido, no que se refere ao estágio I, realizado na educação infantil, o curso dispõe de uma Coordenação de Estágio, cabendo ao coordenador a competência de promover discussões, estudos, atividades e avaliações com os professores da Disciplina de Estágio Supervisionado, se assim for preciso, e com os demais professores, na expectativa de acompanhar a evolução dos trabalhos.

O docente deve acompanhar cada aluno no campo de estágio ao menos 02 (duas) vezes. A avaliação do estagiário é feita em conjunto, entre o professor do Estágio Supervisionado e o professor que recebeu, acompanhou e orientou o Pedagogo. A avaliação acontece por meio de alguns instrumentos, como: projetos de trabalho, atuação profissional, relatório, memorial, artigo e portfólio, dentre outros.

No que se refere à estruturação no Estágio Supervisionado I, deve ter até 10 alunos por professor orientador. A disciplina é realizada em espaços escolares, com carga horária total de 150h, a qual é distribuída da seguinte maneira: 45h para orientação/discussões teórico-metodológicas; 20h para observação direta na sala de aula; $15 \mathrm{~h}$ para planejamento de ações pedagógicas para desenvolver na sala de aula; 50h para regência de classe, sendo 40h de trabalho na sala de aula, diretamente com os alunos, e $10 \mathrm{~h}$ a serem operacionalizadas com outros atores da escola e comunidade; $16 \mathrm{~h}$ para registro e sistematização da experiência; e 4h para avaliação e apresentação na escola campo de estágio. Os objetivos do estágio supervisionado I são:

- Desenvolver um olhar sensível e interpretativo às questões da realidade educacional escolar;

- Conhecer e identificar junto/com os profissionais da escola, uma situação problema relacionada ao processo de ensino-aprendizagem direcionando para questões específicas de conhecimento;

- Estudar situações problema com base em referenciais teóricos (aportes teóricos, proposta pedagógica da escola, proposta curricular da escola) que contribuam com o exercício da práxis pedagógica;

- Planejar e executar ações de intervenção em parceria com a equipe pedagógica da escola campo de estágio (aluno estagiário, professor supervisor de estágio e equipe pedagógica da escola) Podendo se dá de diferentes formas:

- Mini-cursos para professores e ou alunos; 
- Aulas para todos os alunos da turma ou parte deles;

- Ações interventivas no recreio;

- Ações sócio educativas com pais e ou comunidade;

- Projetos de leitura na biblioteca, sala de leitura, laboratórios, brinquedoteca etc;

- Sistematizar a experiência, apresentar e avaliar na escola campo de estágio (PPC do curso de Pedagogia, 2012, p. 62 e 63).

Na próxima seção, farei uma análise da prática pedagógica que venho desenvolvendo neste componente de estágio I, na educação infantil, de 2010 até 2014. Evoco, pois, uma breve discussão sobre a metodologia por mim utilizada, trazendo alguns recortes dos diários de aula que produzi no decorrer deste período.

\title{
3 NARRANDO A METODOLOGIA NO ESTÁGIO NA EDUCAÇÃO INFANTIL: ENTRE OS FIOS DA DOCÊNCIA
}

O método é o caminho, um meio adequado para se chegar a um objetivo. "Na vida cotidiana estamos sempre perseguindo objetivos. Mas estes não se realizam por si mesmos, sendo necessária à nossa atuação, ou seja, a organização de uma sequência de ações para atingi-los [...]" (LIBÂNEO, 1994, p. 150).

Ao iniciar a docência no curso de Pedagogia, minha metodologia era centrada no repasse de conhecimentos. O meu planejamento era fechado, com metas bem definidas, e fugir dele me deixava aflita e tensa.

\begin{abstract}
Hoje aconteceu algo que me desestabilizou, pois como sempre faço, levei meu plano de aula todo estruturado com cabeçalho, objetivos, metodologia, cronograma, conteúdos, recursos, avaliação e referências. Entretanto, utilizaria para esta aula o projetor multimídia, mas por problemas técnicos não pude utilizálo e fiquei muito nervosa em como proceder neste caso. Minha solução foi escrever todos os pontos do texto que tinha destacado nos slides, no quadro-negro. Só após copiar tudo, foi que passei a explicar ponto a ponto (ALEKSANDRA NOGUEIRA, diário (auto) biográfico, Mossoró - RN, 2010).
\end{abstract}

Hoje, percebo como minha compreensão de metodologia era limitada. Não considerava situações adversas e nem a flexibilidade que todo planejamento precisa ter, a depender do contexto. Como afirma Libâneo (1994), os métodos de ensino expressam uma compreensão global do processo educativo na sociedade, como os fins sociais e pedagógicos do ensino, as exigências colocadas pela sociedade, a formação crítica dos alunos e a relevância social dos conteúdos, entre outros aspectos.

Neste sentido, Luckesi (1994), ao discutir sobre as tendências pedagógicas, organiza o conjunto das pedagogias em dois grupos: pedagogia liberal (tradicional, renovada progressivista, renovada não-diretiva e tecnicista) e pedagogia progressista (libertadora, libertária e crítico social dos conteúdos). Posso afirmar que minha prática pedagógica, num momento mais inicial, estava calcada na perspectiva mais tradicional e tecnicista, em que eu aplicava técnicas, passava informações e transmitia a matéria. No entanto, com o passar dos anos, aos poucos, fui me desvinculando desta prática e passei a refletir sobre o meu agir docente. 
Pouco a pouco, passo a compreender que a aprendizagem é algo coletivo e contínuo, sendo preciso ir além da metodologia e dos exercícios e atividades. A nossa prática pedagógica, deve estar centrada na reflexão, a fim da sala de aula tornar-se um espaço de interação e de livre expressão. Pois, como afirma Freire (1996), a prática docente crítica, envolve o pensamento dialético entre o fazer e o pensar sobre o fazer. Logo, na formação permanente do professor, o momento mais relevante é o da reflexão crítica.

Foi justamente com a experiência que comecei a perceber as modificações na minha maneira de dar aulas, abordar os conteúdos e de fazer atividades avaliativas. Aos poucos me desvencilhei das regras preestabelecidas que impunha a mim mesma, como foi o caso que citei na narrativa anterior, em que estava condicionada a um modelo sem, ao menos, refletir sobre as possibilidades de mudanças. Nesse caso:

[...] os próprios professores, no exercício de suas funções e na prática de sua profissão, desenvolvem saberes específicos, baseados em seu trabalho cotidiano e no conhecimento de seu meio. Esses saberes brotam da experiência e são por ela validados. Eles incorporam-se à experiência individual e coletiva sob a forma de habitus e de habilidades, de saber-fazer e de saber-ser. Podemos chamá-los de saberes experienciais ou práticos. [...] (TARDIF, 2012, p. 38-39).

Assim, os saberes experienciais são saberes que não se adquire nas instituições de formação, nem por meio do currículo. São sistematizados em doutrinas ou teorias, são saberes práticos, pois se integram à prática e formam um conjunto de representações a partir das quais os professores interpretam, compreendem e orientam sua profissão e sua prática cotidiana; seria a cultura docente em ação, nas palavras de Tardif (2012).

No início quando comecei a lecionar na Faculdade de Educação da UERN, eu primeiro recorri às memórias de aulas que tive, como os meus professores da graduação ministravam suas aulas, pesquisei sobre metodologias do ensino superior e fiquei atenta ao planejamento que ocorria na FE antes de iniciar o semestre, para ouvir dos professores como costumavam dar aulas. Então, com a minha carga horária em mãos, eu recorria aos referenciais que estavam no programa da disciplina. E a metodologia era basicamente: xerox de textos disponibilizados na copiadora da universidade, aulas expositivas, seminários de textos e avaliações escritas (ALEKSANDRA NOGUEIRA, diário (auto) biográfico, Mossoró - RN, 2014).

Aos poucos, comecei a refletir com mais cuidado sobre a metodologia que utilizava. A partir das próprias reações dos alunos, fui vendo como eles aprendiam com mais prazer. Tive a sensibilidade de ver a diferença do perfil entre os alunos do turno matutino e do noturno, pois, pela manhã, normalmente, chegam com mais energia, o que nem sempre ocorre com os alunos da noite. Alguns deles passam o dia trabalhando e vêm direto para a universidade. Eu percebia isso observando que muitos vinham com as fardas dos respectivos locais de trabalho. Tudo isso passou a entrar no meu planejamento na hora de encaminhar as aulas.

Neste sentido, Libâneo (1994) explica que o planejamento é uma tarefa docente que inclui a previsão das atividades didáticas e coordenação, no que se refere aos objetivos propostos, 
podendo ser adequado e revisado durante o desenrolar da aula. O planejamento é, então, uma maneira de se organizar as ações do professor, mas também é momento de pesquisa e reflexão imbricado à avaliação.

Muito interessante como a profissionalização nos convida a construir respostas, pois, no decorrer do processo, fui confrontada com problemas complexos e variados, como, por exemplo, nas aulas discursivas sobre o fazer do estagiário na educação infantil. Sentia dificuldades em como ensinar a construir recursos didáticos sem fazê-los na prática. Foi daí que surgiu a ideia de fazer oficinas com materiais reutilizáveis. Os alunos colecionavam esse material em casa e traziam para a sala na data estabelecida, para juntos construirmos, inventarmos atividades, pensando na realidade em que iriam atuar, tendo como base o planejamento prévio que haviam elaborado para executarem na regência de classe.

Nesta perspectiva, segundo o PPC do curso de Pedagogia da UERN, o Estágio Supervisionado é compreendido como uma atividade teórica instrumentalizadora da práxis, que não se restringe apenas à aplicação de técnicas e conhecimentos adquiridos na formação acadêmica. É de suma importância, portanto, aprender novas maneiras de enfrentar os problemas, de pesquisar, de ensinar e aprender, sendo este um processo de investigação na ação. O estágio é, pois, uma atividade teórico-prática, em que há um diálogo com os demais componentes do curso. $\mathrm{O}$ objetivo é:

[...] contribuir para a formação de um profissional reflexivo, pesquisador, comprometido com o pensar/agir diante das problemáticas educacionais evidenciadas nos espaços escolares e não escolares, lócus de ação profissional do futuro licenciado. O Estágio configura-se assim, como um espaço de produção do conhecimento que favorece a pesquisa e a extensão através da troca de experiência entre os envolvidos no processo e do aprimoramento progressivo do conhecimento sistematizado, a partir da confluência das diversas atividades curriculares, não se limitando assim, a transferência linear da teoria para a prática (PPC do curso de Pedagogia da UERN, 2012, p. 60).

Assim, tenho desenvolvido, junto às professoras com as quais trabalho diretamente, uma ação desafiadora, que exigiu de nós uma metodologia que orientasse os alunos nas diversas etapas do estágio, são elas: discussão sobre as concepções de estágio; preparação para a observação das escolas de educação infantil; reflexões sobre o Referencial Curricular Nacional para a Educação Infantil - RCNEI; construção dos projetos de ensino e planos de aula; oficinas de recursos didáticos, a partir de materiais reutilizáveis; acompanhamento dos discentes na regência de classe e escrita do portfólio, artigo ou relatório.

As orientações de cada uma dessas etapas mencionadas são feitas, tanto em sala de aula, como por e-mail, ou compartilhadas em um grupo na rede social facebook. Esta última, ganhou corpo em 2014, pois, antes disso, já fazia uso dessa rede social, porém, mais na perspectiva de postar fotos dos momentos vivenciados em sala de aula pelas alunas. Entretanto, em 2014, passamos a utilizá-la de modo mais sistemático, compartilhando atividades, vídeos, sugestões de textos, fotos, projetos de ensino, músicas, jogos didáticos, recursos pedagógicos, entre outros artefatos culturais relacionados à educação infantil. 
Ao iniciar o trabalho com a disciplina de estágio, em 2010, o trabalho final exigido era um relatório no qual os alunos incluíam: os relatos das discussões em sala de aula sobre as concepções de estágio; o projeto de ensino que desenvolviam em relação aos temas a serem trabalhados na regência de classe; os planos de aula, que extraiam do projeto de ensino; os relatos reflexivos do período de regência de aulas ministradas por eles na condição de estagiários.

No entanto, a partir de 2011, comecei a perceber, juntamente com as minhas colegas de trabalho, que os alunos deixavam muito a desejar no quesito reflexão ${ }^{1}$. Eles mais escreviam do que refletiam sobre as experiências vivenciadas em sala de aula. Daí, começamos a pensar numa atividade que desse condição ao aluno de conceber o estágio como um campo de pesquisa, pois "[...] o estágio como pesquisa é, por excelência, um espaço de reflexão sobre a carreira docente. É o momento de rever os conceitos sobre o que é ser professor, para compreender o seu verdadeiro papel da escola na sociedade" (LIMA, 2012, p. 31).

Assim, iniciei o trabalho com portfólios² de formação com os alunos por acreditar que esse recurso favorecia a reflexão dos mesmos sobre o estágio. Realmente, a mudança na metodologia foi positiva, pois passaram a perceber o portfólio como um interlocutor, registrando nele as narrativas diárias vividas na universidade e no chão da escola, incluindo, também, as demais etapas inerentes ao estágio que citei anteriormente.

Tenho plena consciência que trabalhar a pesquisa no estágio é um desafio, sendo preciso entendê-lo como um espaço de intervenção/reflexão. Destarte, o uso dos portfólios tem se mostrado como um excelente aliado para que, tanto o estagiário como eu, entendamos que "é no efetivo exercício da profissão que se aprende e se constroem as especificidades do trabalho docente" (LIMA, 2012, p. 56).

Assim posto, percebo que os alunos têm avançado no sentido de perceberem o estágio como um processo de investigação, em que aliam teoria e prática. "A pesquisa no estágio é uma estratégia, um método, uma possibilidade de formação do estagiário como futuro professor" (PIMENTA; LIMA, 2010, p. 46).

Todavia, no ano de 2014, fui impactada com uma nova metodologia de trabalho. Ao dividir a turma de estágio com uma colega professora, esta sugeriu que nossa didática na disciplina fosse uma continuação do que ela já vinha desenvolvendo com esta turma, em semestres anteriores. A docente havia trabalhado no moodle, um ambiente de aprendizagem virtual, onde os alunos faziam esta interação em sala e também em rede, utilizando a internet.

Trabalho com estágio na educação infantil desde 2010, mas este semestre está sendo diferente, pois me sinto desafiada a ressignificar concepções e metodologias, e isso me impulsiona e mobiliza à novas leituras, pesquisas e debates comigo

\footnotetext{
${ }^{1}$ Aqui, entendo reflexão na concepção de Saviani (1989), quando explicita que esta palavra vem do verbo latino "reflectere" que quer dizer "voltar atrás". Nesta perspectiva, é um re-pensar. Refletir nesta ótica é um pensamento capaz de avaliar impressões e opiniões, ou mesmo conhecimentos científicos e técnicos, questionando-se a respeito do seu significado. [...] Refletir é o ato de retomar, reconsiderar os dados disponíveis, revisar, vasculhar numa busca constante de significado. É examinar detidamente, prestar atenção, analisar com cuidado. [...] (SAVIANI, 1989, p. 23). ${ }^{2}$ Os portfólios não são apenas a seleção dos materiais. É preciso apreciar, analisar, interpretar, construir sentidos, planejar o futuro, criar uma narrativa afinal [...] (BARBOSA; HORN, 2008, p. 112).
} 
mesma, com os meus pares e com os meus alunos (ALEKSANDRA NOGUEIRA, diário (auto) biográfico, Mossoró - RN, 2014).

Aos poucos, constatei que este recurso avaliativo foi adequado para a disciplina de estágio, pois, estágio é um componente que requer muita orientação sobre diversos aspectos: discussão de textos, observação, regência de classe, intervenção na escola e sistematização escrita da atividade, que neste caso, foi um artigo científico.

De fato, um encontro (4 horas) por semana, é pouco tempo para tantas demandas e, neste caso, o uso do ambiente favoreceu esse processo dinâmico que envolve o componente curricular estágio. No entanto, percebi que muitas das alunas não entravam no moodle, por diferentes razões, segundo elas: falta de tempo, devido ao excesso de atividades das diferentes disciplinas que cursavam no semestre; falta de um computador; falta de internet e internet oscilante da UERN, pois, nem sempre, a página carregava, ficando inviável o uso do ambiente em sala de aula.

Estes recursos avaliativos de que tenho feito uso na disciplina de estágio (relatório, portfólio e artigo científico) têm me permitido repensar sobre a prática avaliativa, passando a desmistificar o poder da avaliação exercido sobre os estudantes e de outra visão sobre o meu papel como professora (HOFFMANN, 2003).

Ao trabalhar com estágio na educação infantil percebi que a ação avaliativa é inerente a todo o processo educativo e não apenas a um desses momentos. Daí a necessidade dos trabalhos frequentes e sucessivos ao longo da disciplina. A avaliação, neste sentido, tem a finalidade principal de auxiliar ao aluno, tornando-o partícipe do processo educativo, favorecendo a tomada de consciência nas suas conquistas e dificuldades (HOFFMANN, 2003).

Assim, de 2010 a 2014, como professora de Estágio Supervisionado I - na Educação Infantil, procurei fazer uso de uma avaliação que contemplasse as características teórico-práticas da disciplina, respeitando as diferenças individuais de cada um. As expectativas dos alunos eram muitas, haja vista ser este o primeiro estágio da grade curricular do curso de Pedagogia.

Diante do exposto, ao me questionar sobre o tipo de avaliação que venho desenvolvendo nestes últimos anos, posso afirmar que, dada a metodologia que faço uso, me encontro na avaliação construtivista, pois me posiciono a todo tempo como mediadora do processo ensino-aprendizagem entre o aluno e o conhecimento, por meio do diálogo.

\section{ALGUMAS CONSIDERAÇÕES}

Com a experiência, estudo e relação com os meus pares, tomei consciência que a aprendizagem é algo coletivo, contínuo, que requer problematização (FARIAS, 2009). Imersa nessa prática dialógica, passei a aliar teoria e prática no estágio, foi quando comecei a fazer oficinas de materiais reutilizáveis, no sentido de construir recursos didáticos pedagógicos para serem utilizados no momento da regência de classe na educação infantil. No decorrer desses anos fiz, pois, uso de diferentes instrumentos avaliativos, como relatório, portfólio e artigo.

Reitero que o método (auto) biográfico potencializou o meu desenvolvimento profissional, no sentido de estar sempre em "[...] atitude de pesquisa, de questionamento e busca de soluções 
[...]" (MARCELO, 1999, p. 137). Ou seja, este desenvolvimento não é só do ensino, nem só pessoal, devendo ser o mais holístico possível, relacionado, também, com o desenvolvimento da instituição onde o professor desenvolve sua atividade profissional.

Por conseguinte, pude constatar que a pesquisa contribui para a academia, pois acredito que este estudo possa estar servindo de meio para que a comunidade possa compreender as narrativas (auto) biográficas docentes e/ou discentes como objeto de conhecimento no ensino. Destarte, ficou patente que este método se constitui numa ruptura em relação aos modelos convencionais de investigação nas ciências sociais, pois, como afirma Josso (2010), as práticas de reflexão sobre si, que emanam dos relatos de vida escritos, centrados na formação, proporcionam a formação e a transformação de si.

Observei, ainda, que esta pesquisa oferece uma contribuição social que vai além da academia em si, trazendo a reflexão da prática como estratégia de formação e (auto) formação. Afirmo, então, que qualquer professor, tanto da educação básica como do ensino superior, pode estar em constante reavaliação da sua própria prática, necessitando refletir antes, durante e após a ação. Ao fim, almejo que estas ideias sejam propagadas em todos os níveis da educação.

\section{REFERÊNCIAS}

1. BARBOSA. Maria Carmen Silveira e HORN. Maria da Graça Souza. Projetos pedagógicos na educação infantil. Porto Alegre: Artmed, 2008.

2. FARIAS. Isabel Maria Sabino de. et al. Didática e docência: aprendendo a profissão. Brasília: Líber livro, 2009.

3. FREIRE, Paulo. Pedagogia da autonomia: saberes necessários à prática educativa. São Paulo: Paz e Terra, 1996.

4. HOFFMANN. Jussara Maria Lerch. Avaliação mediadora: uma prática em construção: da préescola à universidade. Porto Alegre: Editora Mediação, 2003.

5. JOSSO, Marie-Christine. Experiência de vida e formação. Tradução de Jos Cláudio e Júlia Ferreira. 2. ed. rev. e amp. Natal: EDUFRN; São Paulo: Paulus, 2010.

6. LIBÂNEO. José Carlos. Didática. São Paulo: Cortez, 1994.

7. LIMA. Maria Socorro Lucena. Estágio e aprendizagem da profissão docente. Brasília: Liber Livro, 2012.

8. LUCKESI. Cipriano Carlos. Filosofia da educação. São Paulo: ed. Cortez, 1994.

9. MARCELO. Carlos Garcia. Formação de professores para uma mudança educativa. Portugal: Porto, 1999.

10. PIMENTA, Selma Garrido; LIMA, Maria do Socorro Lucena. Estágio e docência. 5. ed. São Paulo: Cortez, 2010.

11. SAVIANI. Dermeval. Educação: do senso comum à consciência filosófica. São Paulo: Cortez Editora: Autores Associados, 1989.

12. TARDIF, Maurice. Saberes docentes e formação profissional. 14. ed. Petrópolis: Vozes, 2012. 
13. UNIVERSIDADE DO ESTADO DO RIO GRANDE DO NORTE. Faculdade de Educação. Departamento de Educação. Projeto Pedagógico do Curso de Pedagogia. Mossoró/RN, 2012.

14. VEIGA, Ilma Passos Alencastro. A prática pedagógica do professor de didática. 3. ed. Campinas. São Paulo: Papirus, 1994.

15. ZABALZA. Miguel A. Diários de aula: um instrumento de pesquisa e desenvolvimento profissional. Tradução de Ernani Rosa. Porto Alegre: Artemed, 2004. 